\title{
STRATEGIJE PREVLADAVANJA STRESA KAO PREDIKTORI INTERNET ZAVISNOSTI
}

\begin{abstract}
Apstrakt
Cilj ovog rada je bio da se utvrdi uloga strategija prevladavanja stresa u predviđanju dimenzija internet zavisnosti. Uzorak je prigodan i čini ga 597 ispitanika (63\% žena). Starost ispitanika kreće se u rasponu od 18 do 70 godina a prosečna starost iznosi 34.58 $(S D=11.29)$. U istraživanju je od instrumenata korišćena Kratka verzija Young Testa Internet Zavisnosti za merenje ozbiljnosti kompulsivnog korišćenja interneta i Kratka verzija COPE upitnika za utvrđivanje načina na koji osobe prevladavaju probleme i stresne životne situacije. Sprovedene su dve odvojene hijerarhijske regresione analize. U obema su prediktori u prvom koraku bile sociodemografske varijable a u drugom deset strategija prevladavanja (Samoometanje, Aktivno prevladavanje, Poricanje, Traženje emocionalne podrške, Traženje instrumentalne podrške, Odustajanje, Ventiliranje, Pozitivno redefinisanje, Prihvatanje, Samookrivljavanje), dok su kriterijumske varijable bile različite dimenzije internet zavisnosti (Gubitak kontole/Upravljanje vremenom i Žudnja/Socijalni problemi). Rezultati su pokazali da su oba modela statistički značajna. Kao statistički značajni prediktori dimenzije Gubitak kontrole/Upravljanje vremenom u prvom koraku izdvojila se starost $(\beta=-.13, \mathrm{p}=.001)$, a u drugom Samoometanje $(\beta=.09, \mathrm{p}=.018)$; Aktivno prevladavanje $(\beta=-.15, \mathrm{p}=.001)$; Odustajanje $(\beta=.24, p<.001)$ i Samookrivljivanje $(\beta=.13, p=.002)$. Kada je u pitanju dimenzija Žudnja/Socijalni problemi, kao značajan prediktor u prvom koraku se izdvojila starost $(\beta=-.11, p=.006)$, a u drugom pol $(\beta=.07, p=.041)$; Aktivno prevladavanje $(\beta=$ $-.09, \mathrm{p}=.044)$; Poricanje $(\beta=.14, \mathrm{p}=.001)$; Traženje emocionalne podrške $(\beta=-.16, \mathrm{p}$ $=.002)$ i Odustajanje $(\beta=.25, \mathrm{p}<.001)$. Dakle, možemo da zaključimo da se na osnovu Samoometanja, Aktivnog prevladavanja, Odustajanja i Samookrivljivanja mogu predvideti poteškoće u svakodnevnom funkcionisanju prouzrokovane korišćenjem interneta, ali i da se na osnovu Poricanja, Traženja emocionalne podrške i Odustajanja može predvideti efekat koji preterano korišćenje internet može da ima na socijalne odnose i žudnju za korišćenjem interneta. Primena konfirmatorne faktorske analize ide u prilog konstruktne valjanosti Kratke verzije Young Testa Internet.
\end{abstract}

Ključne reči: strategije prevladavanja stresa, internet zavisnost, upotreba interneta

\footnotetext{
${ }^{1}$ teodora.pavicevic96@gmail.com Citirati rad na sledeći način: Pavićević, T. (2021). Strategije prevladavanja stresa kao prediktori internet zavisnosti. Godišnjak za psihologiju, 18, 59-73. https://doi.org/ 10.46630/gpsi.18.2021.04
} 


\section{Uvod}

Usled ubrzanog tehnološkog razvoja danas je upotreba interneta u velikom porastu. Internet predstavlja jedan od najznačajnijih faktora za učvršćivanje postojećih socijalnih veza, pojačavanje socijalnih aktivnosti, razvoj ličnosti, formiranje identiteta itd. (Toprak et al., 2009; prema Babacan, 2015). Sa druge strane, postoje i autori koji tvrde da je internet zaslužan za razvoj površnih odnosa sa poznanicima i prijateljima, usamljenost, socijalnu izolaciju, depresiju, prestupničko ponašanje i drugo (Brenner, 1997). Ova kontradiktorna shvatanja potiču od radova dveju studija koja su ukazala na postojanje negativnih efekata korišćenja interneta na društvenost (Kraut et al., 1998), ali i na to da ljudi sve manje provode vremena baveći se svakodnevnim aktivnostima, a sve više vremena provode kod kuće ili na poslu koristeći internet (Nie \& Erbring, 2002). Ovi rezultati su kasnije preispitivani, kako od drugih autora, tako i od samih autora u kasnijim studijama (Kraut et al., 2002).

Većina ljudi koristi internet na funkcionalan način. Jedna od karakteristika funkcionalne, neproblematične upotrebe interneta je da se koristi za postizanje $i$ ispunjavanje potreba i ciljeva (Brand et al., 2014). Smatra se da funkcionalni korisnici interneta mogu da prekinu korišćenje onda kada to neke druge obaveze nalažu ili kada se postigne određeni cilj. Drugačije rečeno, korisnici koji na funkcionalan način koriste internet mogu da naprave balans između upotrebe interneta $i$ drugih aktivnosti na način koji odgovara cilju. Međutim, ono što je zabrinjavajuće je da se poslednjih godina pojavio fenomen nefunkcionalnog korišćenja interneta.

Mnogobrojne rasprave se vode u naučnim krugovima koje se tiču odgovarajućeg definisanja ponašanja koje obuhvata prekomernu, negativnu, problematičnu kompulsivnu upotrebu interneta, odnosno internet zavisnosti. Jang (Young, 2004) smatra da internet zavisnost predstavlja impulsivnu težnju za upotrebom interneta, praćenu gubitkom kontrole, preokupiranošću i kontinuiranom upotrebom bez obzira na ispoljene posledice u poremećaju ponašanja. Da bi se neka osoba nazvala internet zavisnikom potrebno je da ispuni pet ili više kriterijuma, od ukupno osam, u trajanju od šest meseci (Young, 2004): 1) okupiranost objektom zavisnosti: 2) tolerancija na upotrebu interneta; 3) pojava simptoma apstinencijalne krize pri pokušaju smanjenja upotrebe ili pri lišavanju interneta; 4) nemogućnost kontrole nad upotrebom interneta; 5) na internetu se ostaje duže ili mu se pristupa češće nego što je planirano; 6) pojava problema u socijalnim odnosima, u školi, na poslu, usled upotrebe interneta; 7) skrivanje realnog vremena koje se provodi na internetu; 8) percipiranje interneta kao načina da se pobegne od problema.

Prema Suleru (Suler, 1999, prema Hinić, 2008) postoje generalni i specifični tip internet zavisnika. Ukoliko su korisnici zavisni od neke specifične aplikacije ili funkcije interneta, kao na primer kupovina preko interneta, igranje igrica, kockanje, sajber seks i pornografija, onda se radi o specifičnom tipu zavisnika, pri čemu najčešće njihova patologija nije uslovljena internetom.

Stevanović (2020) govori o specifičnim problemima koji su u vezi sa problematičnom upotrebom interneta i digitalnim tehnologijama. On govori o tome da je 
poremećaj vezan za igranje igara prvo psihijatrijsko stanje koje je izazvano problematičnom upotrebom interneta, kao i da poremećaj igranja igara i problematična upotreba interneta mogu da uključuju funkcionalne i strukturalne moždane abnormalnosti. Takođe, različite forme problematične upotrebe interneta dovode do psiholoških i kognitivnih promena. Autor zaključuje da iako postoji veza između problematične upotrebe interneta i mentalnih poremećaja, ona još uvek nije u potpunosti jasna.

Sa druge strane, generalni tip zavisnosti predstavlja takav tip zavisnosti da je osoba zavisna od samog interneta, prekomerno ga koristi, bavi se različitim aktivnostima na mreži i ima nezaustavljivu potrebu da to i dalje radi (Suler, 1999, prema Hinić, 2008). Ovaj rad se bavi generalnim tipom internet zavisnosti te će u daljem tekstu biti prikazane značajne teorijske implikacije i raniji empirijski zaključci vezani za ovaj tip.

Problematična upotreba interneta identifikovana je u brojnim studijama i pokazuje da su negativni ishodi poput gubitka posla, akademskog neuspeha i razvoda posledica prekomerne upotrebe interneta (Byun et al., 2009; Chou et al., 2005; Griffiths, 2000a, 2000b; Lortie \& Guitton, 2013; Weinstein \& Lejoyeux, 2010; Widyanto \& Griffiths, 2006).

U našoj zemlji prekomerna upotreba interneta je ispitivana u mnogim istraživanjima i povezivana sa različitim konstruktima. Tako npr. Popadić sa saradnicima (Popadić et al., 2020) dolazi do rezultata koji pokazuju da je vreme provedeno online u pozitivnoj vezi sa prekomernom upotrebom interneta. Pored ovoga rezultati su ukazali da je uglavnom moguće predvideti preterano korišćenje interneta na osnovu anksioznosti adolescenata. Takođe, Rakić-Bajić i Hedrih (2012) ispitivali su prekomernu upotrebu interneta, zadovoljstvo životom i osobine ličnosti. Njihovi rezultati su pokazali da postoji povezanost prekomerne upotrebe interneta sa više osobina ličnosti, ali kada je u pitanju njihov doprinos u predviđanju prekomerne upotrebe interneta, samo Savesnost se izdvojila kao značajan prediktor. Kada je u pitanju zadovoljstvo životom, utvđeno je da je u vezi sa problematičnom upotrebom interneta, ali ne direktno već posredstvom Savesnosti koja predstavlja medijator. Hinić sa saradnicima (Hinić et al., 2020) ispitivao je vezu između problematične upotrebe interneta $\mathrm{i}$ indikatora pozitivne orijentacije kod adolescenata. Rezultati su pokazali da je model kojim se predviđa problematična upotreba interneta na osnovu zadovoljstva životom, samopoštovanja i optimizma/pesimizma statistički značajan, a pesimizam se izdvojio kao najznačajniji prediktor problematične upotrebe interneta.

Faktori koji dovode do prekomerne upotrebe interneta mogu da potiču od konkretnih situacija i osoba, ali mogu i da uključuju negativne misli i osećanja (Suler, 1996). Osećaj depresivnosti, nisko samopoštovanje, bespomoćnosti i pesimizam vezan za budućnost mogu biti značajni faktori koji dovode do adiktivnog ponašanja pomoću kojeg će pojedinci moći makar privremeno pobeći od misli i izbeći suočavanje sa negativnim mislima i osećanjima. Takav oblik ponašanja omogućava osobi da trenutno zaboravi na probleme koji se dešavaju u realnom okruženju i može biti efikasan način za redukciju stresa, međutim, kada takvo ponašanje postane učestalo, u cilju izbegavanja neprijatnih situacija, onda dolazi do pojave još većeg problema (Suler, 1996). Ako osoba očekuje da će je upotreba interneta odvratiti od problema 
ili negativnih osećanja onda je i verovatnije da će koristiti internet u cilju sprečavanja gubitka kontrole, što može rezultirati žudnjom prema korišćenju interneta, lošim upravljanjem vremenom i povećanim socijalnim problemima. Takođe, učestalo korišćenje interneta dovodi do gubitka kognitivne kontrole, koje je uzrokovano posredstvom bihevioralnog funkcionisanja (Brand et al., 2014).

U prilog ovim tvrdnjama govore istraživanja Grifita i Grohola (Griffiths, 1998; Grohol, 1998) u kojima su utvrdili da pojedinci koriste internet kao beg od realnosti ili kao mehanizam prevladavanja u cilju prevazilaženja svakodnevnih problema, kao što su poslovne poteškoće ili zdravstveni problemi.

Prevladavanje se određuje kao kognitivni i bihevioralni napori da se izađe na kraj sa specifičnim spoljašnjim i/ili unutrašnjim zahtevima koje pojedinac tumači kao opterećujući ili koji su toliko teški da prevazilaze resurse kojima pojedinac raspolaže (Lazarus \& Folkman, 1984). Lazarus i Folkman razlikuju prevladavanje usmereno na problem i prevladavanje usmereno na emocije. Ova podela napravljena je na osnovu fokusa aktivnosti usmerenih na prevladavanje. Osim ove podele, strategije prevladavanja možemo podeliti i po metodu, odnosno prema tipu upotrebljene aktivnosti, i to na kognitivne i bihejvioralne oblike prevladavanja. Nezavisno od definicije ili podele, svrha procesa prilagođavanja pojedinca u stresnim i pretećim situacijama je da mu pomogne da se ponovo vrati u stanje ravnoteže. Reakcije povezane sa suočavanjem mogu biti fiziološke, emocionalne, bihevioralne i kognitivne (Baum et al, 1981; Lazarus, 1991; Şahin, 1994, prema Kalkan \& Koc, 2008).

Rezultati ranijih empirijskih istraživanja pokazuju da pojedinci koji su hronično pod stresom, koji su anksiozni ili u stanju pobuđenosti, više vremena provode na internetu (Ögel, 2012, prema Derin \& Bilge, 2016). Takođe, rezultati istraživanja Lin i Tsai (Lin \& Tsai, 2002) pokazuju da internet zavisnici imaju problema u stvarnom životu, kao i to da koriste nefunkcionalne strategije prevladavanja. Kim i saradnici (Kim et al., 2010) otkrili su u drugom istraživanju da internet zavisnici ne mogu da se nose sa stresom, pate od nesanice i imaju visok nivo depresivnih simptoma. Slične rezultate dobili su i Vang, Li i Čang (Whang et al., 2003) koji pokazuju da internet zavisnici više nego obično koriste internet tokom stresa ili kada su depresivni. Takođe, utvrdili su da internet zavisnici ispoljavaju simptome usamljenosti i kompulsivnog poremećaja, kao i da imaju poremećaje u ponašanju.

Erden i Hatun (Erden \& Hatun, 2015) utvrdili su da program usmeren na prevladavanje smanjuje zavisnost od interneta. U sličnom istraživanju, Nedim-Bal i Metan (Nedim-Bal \& Metan, 2015) dolaze do zaključka da su programi grupnog psihološkog savetovanja i prevladavanja imali pozitivan efekat na zavisnost od interneta kod adolescenata.

Pregledom dosadašnjih istraživanja pokazuje se da su autori koristili različite instrumente za operacionalizaciju strategija prevladavanja stresa, ali i internet zavisnosti. Takođe, u navedenim istraživanjima nisu ispitivane specifične strategije prevladavanja koje mogu biti u vezi sa nastankom internet zavisnosti. Zbog svega navedenog, u ovom istraživanju odlučili smo se za koriščenje inventara koji omogućava identifikovanje četrnaest dimenzija prevladavanja stresa, kao i individualno tumačenje svake od njih. Međutim, zbog veoma slabe pouzdanosti četiri dimenzije, 
samo deset dimenzija će biti uključene u analizu. Osim toga, internet zavisnost će biti posmatrana kroz dve subskale, koje pružaju informacije o tome u kojoj meri pojedinac ima probleme u svakodnevnom funkcionisanju koji su izazvani korišćenjem interneta, kao i to u kojoj meri korišćenje interneta deluje na njihove socijalne odnose i pojavu osećaja žudnje prema internet aktivnostima.

S obzirom na prethodno navedeno, osnovno pitanje na koje ovo istraživanje treba da pruži odgovor je da li je na osnovu strategija prevladavanja stresa moguće statistički značajno predvideti dimenzije internet zavisnosti.

Cilj istraživanje tiče se utvrđivanja uloge strategija prevladavanja stresa u predikciji dimenzija internet zavisnosti.

\section{Metod}

\section{Uzorak i procedura}

Uzorak je prigodan i čini ga 597 ispitanika (63\% žena) iz Republike Srbije. Starost ispitanika kreće se u rasponu od 18 do 70 godina, a prosečna starost iznosi $34.58(\mathrm{~S} D=11.29)$. Kada je u pitanju mesto stanovanja, 515 ispitanika je poreklom iz gradske sredine (86.3\%) a 82 je iz seoske sredine (13.7\%).

Podaci su prikupljani online, putem elektronske verzije upitnika. Upitnik je deljen na društvenim mrežama Facebook i Instagram, ali i putem aplikacija Viber i WhatsApp.

\section{Instrumenti}

Kratka verzija Young Testa Internet Zavisnosti (Young Internet Addiction Test - Short Form; YIAT-SF; Pawlikowski et al., 2013) je dizajnirana za adolescente i odrasle i koristi se za merenje ozbiljnosti kompulsivnog korišćenja interneta. Upitnik je baziran na originalnoj verziji razvijen od strane Kimberli Jang (Young, 1998). Skala sadrži 12 tvrdnji. Zadatak ispitanika ja da procene koliko često manifestuju određene oblike ponašanja. Odgovori se beleže na petostepenoj skali Likertovog tipa (od $1=$ Nikad do 5 = Veoma često). Šest tvrdnji se odnosi na Gubitak kontrole/ Upravljanje vremenom. Ovaj predmet merenja tiče se poteškoća u svakodnevnom funkcionisanju prouzrokovanih korišćenjem interneta, (na primer "Koliko često izbegavaš da obaviš kućne poslove kako bi što više vremena proveo na internetu?"). Takođe, sadrži pitanja vezana za negativne posledice izazvane preteranom upotrebom interneta, (na primer "Koliko često dobiješ lošu ocenu zbog preterane upotrebe interneta?"). Osim toga, tiče se i sposobnosti ispitanika da kontrolišu vreme koje provode na internetu, (na primer, "Koliko često ti se dešava da si ostao na internetu duže nego što si planirao?"). Drugi predmet merenja Žudnja/Socijalni problemi, sadrži šest stavki i tiče se efekata koje preterano korišćenje interneta može da ima na socijalne odnose i žudnju za korišćenjem interneta, (na primer, "Koliko često razmišljaš o korišćenju internet kada si offline ili maštaš o tome da si online?"). Takođe ova skala sadrži tvrdnje vezane za interpersonalne probleme i regulisanje raspolože- 
nja (na primer, "Koliko često se osećaš neraspoloženo, depresivno i nervozno kada si offline, a to osećanje se gubi kad budeš online?"). Sve stavke se tiču generalne upotrebe interneta nezavisno od aplikacija ili radnji koje se koriste.

Kratka verzija COPE upitnika (Brief Coping Orientation to Problems Experienced - Brief COPE; Carver, 1997) je dizajnirana za utvrđivanje načina na koji se osobe suočavaju sa stresnim životnim situacijama. Skala sadrži 28 opisa različitih ponašanja u stresnim situacijama. Od ispitanika se traži da se prisete stresnih situacija koje su se dogodile u poslednjih nekoliko meseci i da označe kako procenjuju učestalost svog ponašanja na dati način, u cilju prevladavanja stresa. Odgovori se beleže na četvorostepenoj skali Likertovog tipa $(1=$ Nikad; a $4=\check{C}$ esto $)$. Skala meri 14 načina suočavanja sa stresom: Samoometanje, Aktivno prevladavanje, Poricanje, Zloupotreba supstanci, Emocionalna podrška, Instrumentalna podrška, Odustajanje, Ventiliranje, Pozitivno redefinisanje, Planiranje, Humor, Prihvatanje, Religioznost, Samookrivljavanje. Instrument je na ovom uzorku pokazao dobre metrijske karakteristike za skoro sve dimenzije sa koeficijentom interne konzistencije koji se kreće od $\alpha=.71$ (Samookrivljivanje) do $\alpha=.92$ (Aktivno prevladavanje) dok dimenzije koje nisu pokazale zadovoljavajuću pouzdanost nisu bile uključene $\mathrm{u}$ analizu Zloupotreba supstanci $(\alpha=.52)$; Humor $(\alpha=.47)$; Religioznost $(\alpha=.36)$ i Planiranje $(\alpha=.33)$.

\section{Metode analize podataka}

Od statističkih analiza primenjena je korelaciona analiza i hijerarhijska regresiona analiza. Prediktore su u prvom modelu činile sociodemografske varijable a u drugom su pridodate 10 strategija prevladavanja stresa, (Samoometanje, Aktivno prevladavanje, Poricanje, Traženje emocionalne podrške, Traženje informacione podrške, Odustajanje, Ventiliranje, Pozitivno redefinisanje i Samookrivljavanje), Kriterijumske varijable bile su dimenzije internet zavisnosti Gubitak kontrole/Upravljanje vremenom i Žudnja/Socijalni problemi. Konfirmatorna faktorska analiza u cilju testiranja psihometrijski strukture YIAT-SF upitnika sprovedena u jasp paketu (JASP Team, 2021) korišćenjem metode maksimalne verodostojnosti (ML) oslanjajući se na ustaljene metode i kriterijume provere uklapanja (fita) modela podacima (Brown, 2015).

\section{Rezultati}

Primenom konfirmatorne faktorske analize (Brown, 2015) utvrđeno je da predložena faktorska struktura (Pawlikowski et al., 2013) testa na srpskom jeziku pokazuje dobar fit podacima na uzorku korišćenom u ovom radu (ML $\chi 2$ [df = 53] = 230.01, $\mathrm{p}<.001$; RMSEA $=.075,90 \%$ CI [.065-.085], SRMR $=.047, \mathrm{CFI}=.927$, TLI $=.909)$. Standardizovana faktorska zasićenja svih ajtema kreću se u rasponu od .52 do .78. Ovo predstavlja preliminarne pokazatelje konstruktne valjanosti pomenutog testa na srpskom jeziku.

U Tabeli 1 prikazani su deskriptivni pokazatelji za subskale internet zavisnosti i suočavanja sa stresom. Vrednosti pokazatelja zakrivljenosti (Skjunis) i zaravljeno- 
sti (Kurtozis) nam pokazuju da su sve subskale normalno distribuirane prema blažem kriterijumu ( \pm 2 ; Finney \& DiStefano, 2006).

Tabela 1

Deskriptivno-statističke mere ispitivanih varijabli

\begin{tabular}{lcccccc}
\hline Subskala & Min & Max & $A S$ & SD & Sk & Ku \\
\hline IZ 1 & 6 & 30 & 14.69 & 5.23 & 0.44 & -0.48 \\
IZ 2 & 6 & 30 & 9.13 & 4.29 & 1.85 & 1.96 \\
Samoometanje & 1 & 4 & 2.89 & 0.78 & -0.32 & -0.65 \\
Aktivno prevladavanje & 1 & 4 & 3.44 & 0.61 & -1.05 & 0.89 \\
Poricanje & 1 & 4 & 1.62 & 0.72 & 1.13 & 0.61 \\
Traženje emocionalne podr. & 1 & 4 & 2.93 & 0.84 & -0.38 & -0.67 \\
Traženje instrumental podr. & 1 & 4 & 2.85 & 0.86 & -0.30 & -0.75 \\
Odustajanje & 1 & 4 & 1.67 & 0.72 & 1.08 & 0.76 \\
Ventiliranje & 1 & 4 & 2.64 & 0.73 & -0.13 & -0.46 \\
Pozitivno redefinisanje & 1 & 4 & 3.29 & 0.64 & -0.72 & 0.02 \\
Prihvatanje & 1 & 4 & 3.24 & 0.62 & -0.51 & -0.29 \\
Samookrivljavanje & 1 & 4 & 2.91 & 0.81 & -0.42 & -0.61 \\
\hline
\end{tabular}

Napomena. IZ 1 = Dimenzija internet zavisnosti Gubitak kontrole - Upravljanje vremenom; IZ 2 = Dimenzija internet zavisnosti Žudnja - Socijalni problemi; Min = minimum; $M a x=$ maksimum; $A S=$ aritemtička sredina; $S D=$ standardna devijacija; $S k$ $=$ Skjunis; $K u=$ Kurtozis.

Na osnovu rezultata prikazanih u Tabeli 2 možemo videti da je dimenzija internet zavisnosti Gubitak kontrole/Upravljanje vremenom u pozitivnoj korelaciji srednjeg intenziteta sa strategijom prevladavanja Odustajanje, zatim u pozitivnoj korelaciji niskog intenziteta sa strategijama Samoometanje, Poricanje, Traženje intrumentalne podrške i Samokrivljivanje, dok je u negativnoj korelaciji niskog intenziteta sa strategijom Aktivno prevladavanje. Kada je u pitanju dimenzija internet zavisnosti Žudnja/Socijalni problemi, rezultati pokazuju da je ova dimenzija u srednjoj korelaciji pozitivnog smera sa strategijom Odustajanje, zatim u niskoj korelaciji pozitivnog smera sa strategijama Samoometanje, Poricanje, Ventiliranje i Samookrivljavanje, kao i u negativnoj korelaciji niskog intenziteta sa strategijama Aktivno prevladavanje i Traženje emocionalne pomoći.

Tabela 2

Interkorelacije ispitivanih varijabli

\begin{tabular}{lcccccccccc}
\hline & 1 & 2 & 3 & 4 & 5 & 6 & 7 & 8 & 9 & 10 \\
\hline 1. IZ1 & & & & & & & & & & \\
2. IZ2 & $.62^{* *}$ & & & & & & & & & \\
3. Samoometanje & $.24^{* *}$ & $.19^{* *}$ & & & & & & & & \\
4. Akt. prevladavanje & $-.25^{* *}$ & $-.22^{* *}$ & -.05 & & & & & & & \\
5. Poricanje & $.20^{* *}$ & $.28^{* *}$ & $.28^{*}$ & $-.16^{*}$ & & & & & &
\end{tabular}




\begin{tabular}{llllllllllll} 
6. Traženje emoc.podr. & .01 & $-.09^{*}$ & .07 & $.18^{*}$ & .01 & & & & & \\
7. Traženje instr.podr. & $.08^{*}$ & .01 & $.09^{*}$ & $.12^{*}$ & .05 & $.70^{*}$ & & & & \\
8. Odustajanje & $.40^{* *}$ & $.39^{* *}$ & $.32^{*}$ & $-.44^{*}$ & $.38^{*}$ & -.01 & .07 & & & \\
9. Ventiliranje & $.19^{* *}$ & $.18^{* *}$ & $.29^{*}$ & .02 & $.26^{*}$ & $.16^{*}$ & $.18^{*}$ & $.23^{*}$ & & \\
10. Poz.redefinisanje & -.03 & -.07 & $.09^{*}$ & $.37^{*}$ & -.07 & $.24^{*}$ & $.15^{*}$ & $-.18^{*}$ & $.09^{*}$ & \\
11. Prihvatanje & -.03 & -.03 & -.03 & $.22^{*}$ & $-.14^{*}$ & $.09^{*}$ & .07 & $-.17^{*}$ & .05 & $.27^{*}$ \\
12. Samookrivljavanje & $.28^{* *}$ & $.21^{* *}$ & $.28^{*}$ & $-.11^{*}$ & $.21^{*}$ & -.01 & .05 & $.35^{*}$ & $.27^{*}$ & -.04 \\
\hline
\end{tabular}

Napomena. ${ }^{*} * p<.05 ; * p<.01$; IZ $1=$ Dimenzija internet zavisnosti Gubitak kontrole - Upravljanje vremenom; IZ 2 = Dimenzija internet zavisnosti Žudnja - Socijalni problemi.

\section{Prediktori dimezije Internet zavisnosti Gubitak kontrole/Upravljanje vremenom}

Rezultati hijerarhijske regresione analize (Tabela 3 ) pokazuju da je prvi model, koji sadrži prediktore sociodemografskih karakteristika, statistički značajan $\left(F_{(3,593)}\right.$ $=3.582 ; p=.014)$ i da objašnjava $1.8 \%$ varijanse kriterijuma. Nezavisni doprinos predikciji pokazala je varijabla starost $(\beta=-.13)$.

U drugom modelu su dodate dimenzije strategija prevladavanja stresa, i ovaj se model u celini pokazao kao statistički značajan $\left(F_{(13,583)}=12.744 ; p<.000\right)$, sa procentom objašnjene varijanse od $20.4 \%$. Doprinos predikciji dodatih varijabli je takođe statistički značajan $\left(\Delta F_{(10.583)}=15.235 ; \mathrm{p}<.000\right)$ i objašnjava dodatnih $20.3 \%$ varijanse kriterijuma. Kada je nezavisni doprinos prediktora unutar ovog modela u pitanju, varijabla starost nije više statistički značajan prediktor, a kao značajni prediktori pokazali su se samoometanje $(\beta=.09)$, aktivno prevladavanje $(\beta=-.15)$, odustajanje $(\beta=.24)$ i samookrivljavanje $(\beta=.13)$.

\section{Prediktori dimenzije Internet zavisnosti Žudnja/Socijalni problem}

Rezultati hijerarhijske regresione analize (Tabela 3 ) pokazuju da je prvi model, koji sadrži prediktore sociodemografskih karakteristika, statistički značajan $\left(F_{(3,593)}\right.$ $=3.567 ; p=.014)$ i da objašnjava $1.8 \%$ varijanse kriterijuma. Nezavisni doprinos predikciji pokazala je varijabla starost $(\beta=-.11)$.

U drugom modelu su dodate dimenzije strategija prevladavanja stresa, i ovaj se model u celini pokazao kao statistički značajan $\left(F_{(13,583)}=12.217 ; p<.000\right)$, sa procentom objašnjene varijanse od $21.4 \%$. Doprinos predikciji dodatih varijabli je takođe statistički značajan $\left(\Delta F_{(10,583)}=14.567 ; \mathrm{p}<.001\right)$ i objašnjava dodatnih $19.6 \%$ varijanse kriterijuma. Kada je nezavisni doprinos prediktora unutar ovog modela u pitanju, u drugom modelu varijabla starost je izgubila svoju značajnost iz prethodnog modela $(p>.05)$, a kao značajni prediktori pokazali su se pol $(\beta=.07)$ aktivno prevladavanje $(\beta=-.09)$, poricanje $(\beta=.14)$, emocionalna podrška $(\beta=-.16)$ i odustajanje $(\beta=.25)$. 
Tabela 3

Predikcija dimenzija internet zavisnosti Gubitak kontrole/Upravljanje vremenom $i$ Žudnja/Socijalni problemi

\begin{tabular}{llcccc}
\hline \multirow{2}{*}{ Prediktori } & \multicolumn{2}{c}{$\begin{array}{c}\text { Gubitak kontrole/ } \\
\text { Upravljanje vremenom }\end{array}$} & \multicolumn{2}{c}{$\begin{array}{c}\text { Žudnja/Socijalni } \\
\text { problemi }\end{array}$} \\
\cline { 2 - 6 } Model 1 & Pol & $\beta$ & $p$ & $\beta$ & $p$ \\
& Starost & .01 & .719 & .04 & .246 \\
& Mesto stanovanja & -.13 & .001 & -.11 & .006 \\
Model 2 2 Pol & .02 & .606 & -.03 & .477 \\
& Starost & .06 & .096 & .07 & .041 \\
& Mesto stanovanja & -.06 & .082 & -.07 & .064 \\
& Samoometanje & -00 & .844 & -.03 & .454 \\
& Aktivno prevladavanje & .09 & .018 & .04 & .304 \\
& Poricanje & -.15 & .001 & -.09 & .044 \\
& Emocionalna podrška & .02 & .669 & .14 & .001 \\
& Instrumental podrška & -.04 & .455 & -.16 & .002 \\
& Odustajanje & .07 & .138 & .09 & .102 \\
& Ventiliranje & .24 & .000 & .25 & .000 \\
& Pozitivno redefinisanje & .05 & .187 & .06 & .109 \\
& Prihvatanje & .05 & .239 & .04 & .430 \\
Samookrivljavanje & .04 & .283 & .05 & .167 \\
& .13 & .002 & .04 & .285 \\
\hline
\end{tabular}

Napomena. $\beta=$ standardizovani regresioni koeficijent; Pol: $1=$ muškarci, $2=$ žene; Mesto stanovanja: 1 = urbana sredina, 2 = seoska sredina.

\section{Diskusija}

Osnovni cilj ovog istraživanja je bio da se utvrdi uloga strategija prevladavanja stresa (Samoometanje, Aktivno prevladavanje, Poricanje, Zloupotreba supstanci, Emocionalna podrška, Instrumentalna podrška, Odustajanje, Ventiliranje, Pozitivno redefinisanje, Planiranje, Humor, Prihvatanje, Religioznost i Samookrivljavanje) u predviđanju dimenzija internet zavisnosti (Gubitak kontrole/Upravljanje vremenom i Žudnja/Socijalni problemi). Iz analize su isključene četiri strategije prevladavanja (Zloupotreba supstanci, Planiranje, Humor i Religioznost) zbog nezadovoljavajućih vrednosti koeficijenata interne konzistencije. Sprovedena je hijerarhijska regresiona analiza u cilju kontrole sociodemografskih karakteristika (pol, starost, mesto stanovanja). Utvrđeno je da sociodemografske varijable uključene u prvi korak hijerarhijske regresione analize, imaju značajan ali mali doprinos predikciji dimenzija internet zavisnosti. Što se tiče ostalih prediktora uključenih u oba modela pokazalo se da imaju značajan zajednički doprinos u predviđanju dimenzija Gubitak kontrole/ Upravljanje vremenom i Žudnja/Socijalni problemi, U toj kombinaciji one objašnjavaju 20.4\% varijanse skora na dimenziji Gubitak kontrole/Upravljanje vremenom, odnosno $21.4 \%$ na dimenziji Žudnja/Socijalni problemi. Nezavisan doprinos u 
predviđanju Gubitka kontrole/Upravljanja vremenom imaju strategije Samoometanje, Odustajanje i Samookrivljivanje kao prediktori pozitivnog smera i Aktivno prevladavanje kao prediktor negativnog smera. Što se tiče dimenzije Žudnja/Socijalni problemi kao nezavisni prediktori izdvojili su se strategije Poricanje i Odustajanje čiji je smer pozitivan kao i Aktivno prevladavanje i Traženje emocionalne podrške čiji je smer negativan.

Pojedini autori govore o povezanosti između povećanog nivoa stresa kod odraslih (Deatherage et al., 2014) i stresnih životnih događaja kod adolescenata (Leung, 2006) sa pojavom internet zavisnosti. Rezultati istraživanja u kome su učestvovali studenti utvrdili su postojanje jake povezanosti pozitivnog smera između stresa, anksioznosti i depresivnosti sa jedne strane i internet zavisnosti sa druge strane (Akin \& İskender, 2011). Prema tome, internet zavisnost može biti povezana sa povećanim nivoima psihološkog distresa koji obuhvata niz psiholoških stanja. Međutim, efekat ovih faktora rizika može biti ublažen ili pojačan u zavisnosti od načina na koji se pojedinci suočavaju sa stresom.

Korišćenje interneta može se sagledati i kao odgovor na suočavanje sa emocionalnim i socijalnim problemima (Bernardi \& Pallanti, 2009). Internet se često preterano koristi onda kada je potrebno da se suočimo sa nekim neprijatnim događajima, međutim, ako se uobičajene strategije prevladavanja nedovoljno ili na neadekvatan način koriste, to može predstavljati veliki rizik za pojavu internet zavisnosti. Pojedinac se iznova okreće upotrebi interneta kao glavnom sredstvu za izbegavanje negativnih osećanja i na taj način formira ustaljen obrazac reagovanja u situacijama koje u njemu bude negativne emocije (Muller et al., 2014).

Rezultati dobijeni ovim istraživanjem su donekle u skladu sa prethodno navedenim empirijskim nalazima. Naime, utvrđeno je da su viši skorovi na Odustajanju, Samoometanju, Poricanju, Traženje instrumentale podrške i Samookrivljavanje, povezani sa višim skorovima na dimenziji internet zavisnosti Gubitak kontrole/Upravljanje vremenom, dok su viši skorovi na Aktivnom prevladavanju povezani sa nižim skorovima na dimenziji Gubitak kontrole/Upravljanje vremenom. Drugačije rečeno, ako je reakcija pojedinca na stresne događaje maladaptivna, odnosno, ako zanemaruje problem baveći se nekim drugim aktivnostima, odbija da prihvati da se nešto desilo i često donosi unutrašnje atribucije, može se reći da će imati više poteškoća u svakodnevnom funkcionisanju prouzrokovanih korišćenjem interneta. Sa druge strane, ako osoba aktivno rešava problem imaće bolju moć upravljanja vremenom koje provodi na internetu.

Takođe, rezultati su pokazali da više skorove na Odustajanju, Samoometanju, Poricanju, Ventiliranju i Samookrivljavanju prati povišenje skora na dimenziji Žudnja/ Socijalni problemi, dok aktivno prevladavanje i Traženje emocionalne podrške prati sniženje skora na dimenziji Žudnja/Socijalni problemi. Prema tome, što je reakcija pojedinca na stresnu situaciju maladaptivnija, ako pribegava obavljanju nekih drugih aktivnosti kako ne bi mislila o problemu ili ne želi da prihvati da problem postoji, to ona više žudi za internetom i ispoljava veće probleme u socijalnim odnosima.

$\mathrm{S}$ druge strane, ako pojedinac teži ka tome da rešava probleme i traga za socijalnom podrškom, imaće manje problema u socijalnim odnosima povezanih sa upotrebom interneta. 
Dobiveni rezultati su ukazali da je moguće značajno predvideti obe dimenzije internet zavisnosti (Gubitak kontrole/Upravljanje vremenom i Žudnja/ Socijalni problemi) na osnovu strategija prevladavanja stresa. Kao značajni prediktori prvog modela koji se odnosio na dimenziju Gubitak kontrole/Upravljanje vremenom izdvojili su se Samoometanje, Odustajanje i Samookrivljavanje, kao prediktori pozitivnog smera, a Aktivno prevladavanje kao značajan prediktor negativnog smera. To upućuje na zaključak da će pojedinac imati poteškoće u svakodnevnom funkcionisanju prouzrokovane korišćenjem interneta, kao i negativne posledice usled učestale upotrebe ako: 1) zanemaruje postojanje problema baveći se aktivnostima kojima će pokušati da zavara sebe da problem ne postoji; 2) ima slabe reakcije na situacije koje zahtevaju preduzimanje akcije u cilju rešavanja problema; 3) smatra isključivo sebe odgovornim za neprijatne događaje koji su se desili. Sa druge strane, pojedinac će biti u stanju da upravlja vremenom koje provodi na internetu ako probleme aktivno rešava, odnosno traga za rešenjima. Što se tiče drugog modela, u kome je prediktor bio dimenzija internet zavisnosti Žudnja/Socijalni problemi, kao značajni prediktori pozitivnog smera su se izdvojili Poricanje i Odustajanje, a kao značajan prediktor negativnog smera Traženje emocionalne podrške. Ovo govori o tome da će pojedinac osećati žudnju za korišćenjem interneta i da će imati interpersonalne probleme ukoliko: 1) ima sklonost da poriče postojanje određenog problema; 2) se bavi različitim aktivnostima koje će ga odvratiti od misli koje ukazuju na postojanje problema. Takođe, pojedinac će imati manje interpersonalnih problema izazvanih korišćenjem interneta i biće uspešniji pri regulaciji raspoloženja, ako kraj sebe ima nekoga ko će mu pružiti podršku, razumevanje i iskazati empatiju.

U prilog rezultatima ovog istraživanja govori rad Kusa i saradnika (Kuss et al., 2016) u kome su ispitivali doprinos strategija prevladavanja stresa u predviđanju preterane upotrebe interneta. Oni su utvrdili da strategije prevladavanja Samoometanje, Poricanje, Korišćenje supstanci, Samookrivljavanje, Ventiliranje, Korišćenje emocionalne i Instrumentalne podrške i Odustajanje, predstavljaju statističke značajne prediktore preteranog korišćenja interneta.

Rezultati ovog istraživanja upućuju na značaj strategija prevladavanja stresa u predviđanju internet zavisnosti. Ono što je potrebno naglasiti tiče se problema kategorizacije strategija prevladavanja u kategorije „,na problem usmerene“, „na emocije usmerene“, ,adaptivne“ ili „maladaptivne“. Naime, sam autor ovog testa je istakao da se ove strategije ne mogu sagledavati kategorijalno, već da se njihovom tumačenju treba pristupiti individualno (Carver, 1997). Iz tog razloga sa oprezom treba izvoditi zaključak o tome na koji način se pojedinac treba suočavati sa problemima i prevladavati stres izazvan njima kako ne bi razvio internet zavisnost. Takođe, problem predstavlja nedovoljna razlika između pojmova koji se tiču internet zavisnosti, te se često koriste različiti pojmovi kao sinonimi (patološko korišćenje interneta, kompulsivno korišćenje interneta) ili se pak isti pojmovi objašnjavaju i definišu na različiti način.

Ograničenja ovog rada se odnose na činjenicu da oba instrumenta korišćena u ovom istraživanju nisu adaptirane verzije ovih upitnika na našoj populaciji, već se radi o prevodu ajtema na srpski jezik. Iako je u radu u cilju provere validnosti testa 
internet zavisnosti (IAT) izvršena konfirmatorna faktorska analiza, čiji nalazi idu u prilog valjanosti verzije skale na srpskom jeziku korišćene u ovom istraživanju, predlog budućim autorima tiče se ispitivanja daljih metrijskih karakteristika poput merne invarijantnosti strukture testa kao i veze sa drugim varijablama.

\section{Reference}

Akin, A., \& İskender, M. (2011). Internet Addiction and Depression, Anxiety and Stress. International Online Journal of Educational Sciences, 3(1), 138-148.

Babacan, Mehmet. (2016). The Relationship of Social Media Usage Areas and Addiction. Addicta: The Turkish Journal on Addictions 3. 9-30. https://doi.org/10.15805/ addicta.2016.3.0017

Baum, A., Singer, J. E., \& Baum, C. S. (1981). Stress and the environment. Journal of Social Issues, 37(1), 4-35. https://doi.org/10.1111/j.1540-4560.1981.tb01056.x

Bernardi, S., \& Pallanti, S. (2009). Internet addiction: a descriptive clinical study focusing on comorbidities and dissociative symptoms. Comprehensive Psychiatry, 50(6), 510-516. https://doi.org/10.1016/j.comppsych.2008.11.011

Brand, M., Laier, C., \& Young, K. S. (2014). Internet addiction: coping styles, expectancies, and treatment implications. Frontiers in Psychology, 5, Article 1256. https://doi. org/10.3389/fpsyg.2014.01256

Brenner, V. (1997). Psychology of computer use: XLVII. parameters of Internet use, abuse and addiction: the first 90 days of the Internet Usage Survey. Psychological Reports, 80(3, Pt 1), 879-882. https://doi.org/10.2466/pr0.1997.80.3.879

Brown, T. A. (2015). Confirmatory factor analysis for applied research (2nd ed.). The Guilford Press.

Byun, S., Ruffini, C., Mills, J. E., Douglas, A. C., Niang, M., Stepchenkova, S., \& Blanton, M. (2009). Internet addiction: Metasynthesis of 1996-2006 quantitative research. CyberPsychology \& Behavior, 12(2), 203-207. https://doi.org/10.1089/ cpb.2008.0102

Carver C. S. (1997). You want to measure coping but your protocol's too long: Consider the brief COPE. International Journal of Behavioral Medicine, 4(1), 92-100. DOI: https://doi.org/10.1207/s15327558ijbm0401_6

Chou, C., Condron, L., \& Belland, J. C. (2005). A Review of the Research on Internet Addiction. Educational Psychology Review 17, 363-388. http://dx.doi.org/10.1007/ s10648-005-8138-1

Deatherage, S., Servaty-Seib, H. L., \& Aksoz, I. (2014). Stress, coping, and internet use of college students. Journal of American College Health, 62(1),40-46. https://doi.org/ 10.1080/07448481.2013.843536

Derin, S. \& Bilge, F. (2016). Ergenlerde İnternet Bağımlılığı ve Öznel İyi Oluş Düzeyi . Turkish Psychological Counseling and Guidance Journal, 6(46), 35-51. Preuzeto sa: https://dergipark.org.tr/en/pub/tpdrd/issue/42744/515910 
Erden, S., \& Hatun, O. (2015). The Use of cognitive-behavioral therapy in coping with internet addiction: A case study. Addicta: The Turkish Journal on Addictions, 53-83. https://doi.org/10.15805/addicta.2015.2.1.015

Finney, S. J., \& DiStefano, C. (2006). Nonnormal and Categorical Data in Structural Equation Models. In G. R. Hancock, \& R. O. Mueller (Eds.), A Second Course in Structural Equation Modeling (pp. 269-314). Information Age.

Griffiths, M. (1998). Internet addiction: Does it really exist? In J. Gackenbach (Ed.), Psychology and the Internet: Intrapersonal, interpersonal, and transpersonal implications (pp. 61-75). Academic Press.

Griffiths, M. (2000a). Does Internet and computer "addiction" exist? Some case study evidence. CyberPsychology \& Behavior, 3(2), 211-218. https://doi. org/10.1089/109493100316067

Griffiths, M. (2000b). Internet Addiction - Time to be Taken Seriously? Addiction Research, 8(5), 413-418. https://doi.org/10.3109/16066350009005587

Grohol, J. M. (1998). Professional development, pathology, and psychotherapy on-line. In J. Gackenbach (Ed.), Psychology and the Internet: Intrapersonal, interpersonal, and transpersonal implications (pp.111-140). Academic Press.

Hinić, D. (2008). Korisnički profil internet zavisnika u Srbiji, Psihologija, 41(4), 435453. https://doi.org/10.2298/PSI0804435H

Hinić, D., Zotović, M., Beara, M., \& Rakić-Bajić, G. (2020). Relationship of problematic internet use and positive orientation indicators in adolescents. Psihologija, 53(4), 341-357. https://doi.org/10.2298/PSI190720018H

JASP Team (2021). JASP (Version 0.14.1)[Computer software]. https://jasp-stats.org/

Kalkan, M. \& Koç, H. (2008). Psikolojik Dogum Sırası Bireylerin Stresle Basa Çıkma Stratejilerinin Yordayıc1s1 midir? . Turkish Psychological Counseling and Guidance Journal, 3(30), 45-59. Preuzeto sa: https://dergipark.org.tr/en/pub/tpdrd/ issue $/ 21450 / 229846$

Kim, J. H., Lau, L. U., Cheuk, K. K., Kan, L., Hui, H. L. C., \& Griffiths S. M. (2010). Brief report: Predictors of heavy Internet use and associations with health-promoting and health risk behaviors among Hong Kong university students Journal of Adolescence, 33(1), 215-220. https://doi.org/10.1016/j.adolescence.2009.03.012

Kraut, R., Kiesler, S., Boneva, B., Cummings, J., Helgeson, V., \& Crawford, A. (2002). Internet paradox revisited. Journal of Social Issues, 58(1), 49-74. https://doi. org/10.1111/1540-4560.00248

Kraut, R., Patterson, M., Lundmark, V., Kiesler, S., Mukophadhyay, T., \& Scherlis, W. (1998). Internet paradox: A social technology that reduces social involvement and psychological well-being? American Psychologist, 53(9), 1017-1031. https://doi. org/10.1037//0003-066x.53.9.1017

Kuss, D., Dunn, T., Wölfling, K., Müller, K., Hedzelek, M. \& Marcinkowski, J. (2017). Excessive Internet use and psychopathology: The role of coping. Clinical Neuropsychiatry, 14(1), 73-81.

Lazarus, R. S. (1991). Emotion and adaptation. Oxford University Press.

Lazarus, R.S, \& Folkman, S. (1984). Stress, Appraisal, and Coping. Springer Publishing Company. 
Leung, L. (2006). Stressful life events, motives for Internet use, and social support among digital kids. CyberPsychology \& Behavior 10(2) 204-214. https://doi.org/10.1089/ cpb.2006.9967

Lin, S., \& Tsai, C. C. (2002). Sensation seeking and internet dependence of Taiwanese high school adolescents. Computers in Human Behavior, 18(4), 411-426. https://doi. org/10.1016/S0747-5632(01)00056-5

Lortie, C. L., \& Guitton, M. J. (2013). Internet addiction assessment tools: Dimensional structure and methodological status. Addiction, 108(7), 1207-1216. https://doi. org/10.1111/add.12202

Müller, K. W., Glaesmer, H., Brahler, E., Woelfling, K., \& Beutel, M. E. (2014). Prevalence of Internet Addiction in the General Population: Results from a German Population-Based Survey. Behaviour \& Information Technology, 33, 757-766. https://doi.org/10.1080/0144929X.2013.810778

Nedim-Bal, P., \& Metan, H. (2016). The effect of computer addiction management psycho training program on 9th grade students. Abant İzet Baysal Üniversitesi Eğitim Fakültesi Dergisi, 16(1), 62-74. https://doi.org/10.17240/aibuefd.2016.16.1-5000182911

Nie, N., \& Erbring, L. (2002). Internet and Society: A Preliminary Report. IT \&Society, $1(1), 275-283$.

Pawlikowski, M., Altstötter-Gleich, C., \& Brand, M. (2013). Validation and psychometric properties of a short version of Young's internet addiction test. Computers in Human Behavior, 29(3), 1212-1223. https://doi.org/10.1016/j.chb.2012.10.014

Popadić, D., Pavlović, Z., \& Kuzmanović, D. (2019). Intensive and excessive Internet use: Different predictors operating among adolescents. Psihologija, 53(3), 273-290. https://doi.org/10.2298/PSI190805003P

Rakić-Bajić, G. i Hedrih, V. (2012). Prekomjerna upotreba interneta, zadovoljstvo životom i osobine ličnosti. Suvremena psihologija, 15(1), 119-131. https://hrcak.srce.hr/84664

Stevanović, D. (2020). Introduction to the Special Issue on problematic behaviors related to Internet use: Facts, conjectures, and oranges. Psihologija, 53(3), 225-236. https:// doi.org/10.2298/PSI200413015S

Suler, J. (1996, August). Why is This Thing Eating My Life? Computer and cyberspace Addiction at the "Palace". The psychology of cyberspace. http:// wwwl.rider.edu/ suler/psycyber/eatlife.html/

Weinstein, A., \& Lejoyeux, M. (2010). Internet addiction or excessive internet use. The American Journal of Drug and Alcohol Abuse, 36(5), 277-283. https://doi.org/10.31 09/00952990.2010.491880

Whang, L., Lee, H., \& Chang, G. (2003). Internet over-users' psychological profiles: A behavior sampling analysis on internet addiction. CyberPsychology \& Behavior, 6(2),143-150. https://doi.org/10.1089/109493103321640338

Widyanto, L., \& Griffiths, M. D. (2006). Internet addiction: A critical review. International Journal of Mental Health and Addiction, 4, 31-51. https://doi.org/10.1007/ s11469-006-9009-9

Young, K. S. (2004). Internet addiction: A new clinical phenomenon and its consequences. American Behavioral Scientist, 48(4), 402-415. https://doi. org/10.1177/0002764204270278 


\title{
Teodora Pavićević
}

Faculty of Philosophy

University of Nišu

Niš, Serbia

\section{COPING STRATEGIES AS A PREDICTOR OF INTERNET ADDICTION}

\begin{abstract}
The aim of this study was to determinate the role of coping strategies in predicting internet addiction dimensions. The sample is conveniente and it consists of 597 subjects (63\% women). The age of the subject ranges from 18 to 70 years, with an average age of $35.58(\mathrm{SD}=11.29)$. To measure a severity of compulsive internet use Young Internet Addiction Test-Short Form; YIAT-SF was used, and Brief Coping Orientation to Problems Experienced; Brief COPE was used to measure how people cope with problems and stressful life events. Two separate hierarchical regression analyses were conducted. In both analyses, in first step the predictors were sociodemographic variables, and in second were ten types of coping strategies (Self-distraction, Active coping, Denial, Use of emotional support, Use of instrumental support, Behavioral disengagement, Venting, Positive reframing, Acceptance and Self-blame), while the criteria variables were different dimensions of internet addiction (Loss of control/Time management and Craving/Social problems). The results showed that both models are statistically significant. Significant predictor of dimension Loss of control/Time management in the first step is age $(\beta=-.13, p=.001)$, and in second step are Self-distraction $(\beta=.09, p=$ $.018)$; Active coping $(\beta=-.15, p=.001)$; Behavioral disengagement $(\beta=.24, p<.001)$ and Self-blame $(\beta=.13, p=.002)$. When it comes to Craving/Social problems, significant predictor of this variable in first step is age $(\beta=-.11, p=.006)$, and in second are gender $(\beta=.07, p=.041)$; Active coping $(\beta=-.09, p=.044)$; Denial $(\beta=.14, p=.001)$; Use of emotional support $(\beta=-.16, p=.002)$ and Behavioral disengagement $(\beta=.25$, $\mathrm{p}<.001)$. So, based on the results, we can conclude that based on Self-distraction, Active coping, Behavioral disengagement, and Self-blame we can predict the difficulties in everyday functioning caused by internet use, but we can also predict an effect that excessive internet use could have on social relations and craving for the Internet based on Denial, Use of emotional support and Behavioral disengagement. The application of Confirmatory Factor Analysis suggested good construct validity of Young Internet Addiction Test-Short Form.
\end{abstract}

Keywords: coping strategies, internet addiction, internet use

Primljeno: 30.04 .2021 .

Primljena korekcija: 16.09.2021.

Prihvaćeno za objavljivanje: 22.09.2021.

\footnotetext{
${ }^{2}$ teodora.pavicevic96@gmail.com

Please cite as: Pavićević, T. (2021). Strategije prevladavanja stresa kao prediktori internet zavisnosti [Coping strategies as a predictor of internet addiction] . Godišnjak za psihologiju, 18, 59-73. https://doi. org/ 10.46630/gpsi.18.2021.04
} 